\title{
The Expansion of Associated Health Training
}

\section{in the VA}

\author{
Erin L. Patel, PsyD, ABPP; Jeffrey M. Bates, PhD; Jocelyn K. Holguin, MSW; Stacy D. Pommer, MSW; \\ Samuel S. King, MS, MDiv; Paul B. Greenberg, MD, MPH; Anthony P. Albanese, MD, DFASAM; \\ Karen M. Sanders, MD; and Marjorie A. Bowman, MD, MPA
}

\begin{abstract}
Purpose: Approximately 21,000 US Department of Veterans Affairs (VA) health professions trainees per year are in associated health $(\mathrm{AH})$ occupations. We describe the VA Office of Academic Affiliation's expansion of $\mathrm{AH}$ education in recent years and highlight the importance of increasing $\mathrm{AH}$ education broadly in the United States. Our focus is on the growing role of $\mathrm{AH}$ education in the $\mathrm{VA}$ over the past decade by describing the demand for $\mathrm{AH}$ professionals in all clinical settings; scope of funded $\mathrm{AH}$ training in the VA; and targeted AH education expansion efforts.
\end{abstract}

Observations: The VA provides clinical training for more than $40 \mathrm{AH}$ professions and provides funding for 17 of these professions. Expansion efforts in $\mathrm{AH}$ over the past 10 years have yielded a $33 \%$ increase in stipendfunded positions and targeted interprofessional training, VA strategic initiatives, rural populations, and conversion of pregraduate-degree positions to postgraduate-degree positions.

Conclusions: In order to meet the complex health care needs of our nation, continued attention to interprofessional care and health professions education is of paramount importance. The VA has worked to address these broad needs and to meet the needs of veterans through increasing stipendfunded $\mathrm{AH}$ training positions by $33 \%$ and directly targeting high-need clinical areas. Ongoing expansion is anticipated in the areas of postgraduate-degree training and rural training.
Author affiliations can be found at the end of the article.

Correspondence:

Erin Patel

(erin.patel@va.gov)

Fed Pract. 2021;38(8). Published online August 17. doi:10.12788/fp.0163
T he US Department of Veterans Affairs (VA) is the largest health care delivery system in the United States, comprising 1293 sites of care, including 171 medical centers. ${ }^{1}$ One of the 4 statutory missions of the VA is to train health care professionals (HCPs) to meet the needs of the VA and the nation. ${ }^{2}$ Through partnerships with more than 1800 accredited colleges, universities, and training programs, the VA provides training annually to nearly 118,000 health professions trainees (HPTs) across a variety of health care professions, and all of whom provide direct clinical care to veterans. ${ }^{3}$

In the VA, the Office of Academic Affiliations (OAA) is charged with overseeing health professions training and the VA's partnership with medical and associated health (AH) professions schools, which was first codified in Policy Memorandum No. 2 in 1946. ${ }^{4,5}$ Given the scope and breadth of health professions education offered through the VA, OAA is in a unique position to address health care shortage areas as well as influence the educational standards for certain professions.

Many of these health care professions fall under the rubric of $\mathrm{AH}$, which include mental health (MH) specialties, rehabilitative specialties, and others. These professions are critical to address in the expanding world of health care in the United States with its increased specialization and emphasis on coordination of care with interprofessional teams. During the 2019/2020 academic year, the VA provided clinical training to approximately 21,000 AH HPTs from $>40$ professions with just over $20 \%$ receiving financial support through the OAA. Of the HPTs who train at VA without compensation, most spend shorter amounts of time in clinical rotations in the VA, are in pregraduate-degree education programs where payment for clinical rotations is not expected and may not be eligible for hire immediately on completion of their clinical training experience. The 17 funded professions have been strategically selected by the OAA to ensure a robust pipeline of HCPs to meet the needs of veterans and the nation.

To meet the demands of AH professionals (AHPs), the OAA implemented targeted expansion over the past 10 years. While not exhaustive, this paper describes several expansion efforts based on VA special initiatives, including enhancing clinical access in rural settings and shifting toward postgraduatedegree training and specialization. By aligning expansion with VA priorities as well as trends in health care more broadly, the OAA can ensure that there is a supply of well-trained 
TABLE OAA AH Education Funded Professions: Academic Year 2020/2021 and Projected Growth

\begin{tabular}{|c|c|c|c|c|}
\hline Specialties Professions & $\begin{array}{l}\text { Training } \\
\text { Level }\end{array}$ & $\begin{array}{l}\text { Funded } \\
\text { Positions }\end{array}$ & $\begin{array}{c}\text { Total } \\
\text { Funding, } \$^{\mathrm{a}}\end{array}$ & $\begin{array}{l}\text { Projected Growth: } \\
2019-2029, \%^{\mathrm{b}}\end{array}$ \\
\hline \multicolumn{5}{|l|}{ Rehabilitation } \\
\hline Audiology & Doctoral & 94 & $4,093,809$ & 13 \\
\hline Blind rehabilitation & Master's intern & 83 & 609,457 & 10 \\
\hline Chiropractic & Resident & 10 & 475,300 & 4 \\
\hline Occupational therapy & $\begin{array}{l}\text { Master's intern } \\
\text { Fellow }\end{array}$ & $\begin{array}{c}193 \\
5\end{array}$ & $\begin{array}{l}1,212,720 \\
227,043\end{array}$ & 16 \\
\hline Nutrition/dietetics & $\begin{array}{c}\text { Postbaccalaureate } \\
\text { Combined master's } \\
\text { Fellow }\end{array}$ & $\begin{array}{c}128 \\
103 \\
2\end{array}$ & $\begin{array}{l}1,230,650 \\
1,051,993 \\
28,704\end{array}$ & 8 \\
\hline Orthotics/prosthetics & Resident & 20 & 893,865 & 17 \\
\hline Physical therapy & $\begin{array}{l}\text { Doctoral intern } \\
\text { Resident }\end{array}$ & $\begin{array}{l}205 \\
42\end{array}$ & $\begin{array}{l}1,173,113 \\
2,246,818\end{array}$ & 18 \\
\hline Speech pathology & $\begin{array}{l}\text { Master's intern } \\
\text { Fellow }\end{array}$ & $\begin{array}{l}41 \\
43\end{array}$ & $\begin{array}{c}187,862 \\
2,062,048\end{array}$ & 25 \\
\hline \multicolumn{5}{|l|}{ Mental Health } \\
\hline Chaplain & Resident & 154 & $6,017,712$ & 4 \\
\hline $\begin{array}{l}\text { Professional mental health } \\
\text { counseling }\end{array}$ & Master's intern & 41 & 262,700 & 25 \\
\hline Marriage and family therapy & Master's intern & 14 & 96,010 & 22 \\
\hline Psychology & $\begin{array}{l}\text { Doctoral intern } \\
\text { Postdoctoral resident }\end{array}$ & $\begin{array}{l}711 \\
453\end{array}$ & $\begin{array}{l}24,541,472 \\
26,524,525\end{array}$ & 3 \\
\hline Social work & $\begin{array}{l}\text { Master's intern } \\
\text { Fellow }\end{array}$ & $\begin{array}{c}1032 \\
16\end{array}$ & $\begin{array}{l}6,812,344 \\
640,447\end{array}$ & 13 \\
\hline \multicolumn{5}{|l|}{ Other } \\
\hline Optometry & $\begin{array}{l}\text { Resident } \\
\text { Fellow }\end{array}$ & $\begin{array}{c}218 \\
4\end{array}$ & $\begin{array}{c}9,675,854 \\
242,218\end{array}$ & 4 \\
\hline Pharmacy & $\begin{array}{c}\text { Resident } \\
\text { Postdoctoral fellow }\end{array}$ & $\begin{array}{c}621 \\
5\end{array}$ & $\begin{array}{c}32,819,351 \\
283,831\end{array}$ & -3 \\
\hline Physician assistant & Resident & 32 & $2,895,438$ & 31 \\
\hline Podiatry & $\begin{array}{c}\text { Resident } \\
\text { Affiliated-sponsored resident }{ }^{c} \\
\text { Fellow }\end{array}$ & $\begin{array}{l}207 \\
29.4 \\
1\end{array}$ & $\begin{array}{c}12,366,907 \\
\text { N/A } \\
67,784\end{array}$ & 0 \\
\hline Total & & 4527 & $138,739,975$ & \\
\hline
\end{tabular}

Abbreviations: AH, associated health; OAA, US Department of Veterans Affairs Office of Academic Affiliations. aWithout locality pay adjustments.

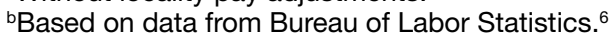

cPaid via disbursement mechanism to the affiliate sponsor.

AHPs who have developed the requisite competencies to contribute to our nation's health care needs. Further, expansion can help train and recruit health professionals who can be hired into VA positions ready to care for the complex needs of veterans.

\section{ASSOCIATED HEALTH PROFESSIONALS}

Overseen by the OAA, AH expansion is designed to address the specific needs of the VA and the US health care system. Data from the VA Workforce Management and Consulting (WMC) shows that the VA 
employment of AHPs has grown from 87,351 AHPs hired in fiscal year (FY) 2010 to 119,120 as of April 2020. This represents an average yearly growth rate of $3.4 \%$ and a total growth rate of $36 \%$. The Bureau of Labor Statistics predictions for 2019/2029 suggest that certain AHPs are expected to have a 10 -year growth rates of $20 \%$ or more to meet the changing health care needs of patients especially as the population ages; the growth rates for many AHPs far surpasses that of physicians, which is anticipated to be $4 \%$ (Table). ${ }^{6,7}$ The VA WMC expects an additional 52,283 AHPs will be hired by the VA by FY 2030 based on the 10-year average growth rate (Kali Clark, Veterans Health Administration Workforce Management and Consulting Office, email communication, May 28, 2020).

One of the driving forces behind the growth rate is the move toward using AHPs to supplement health care for a variety of health conditions. ${ }^{89}$ Examples include the integration of rehabilitation professionals, alternative care professionals (eg, massage therapists, practitioners who offer training in yoga and meditation), chiropractors, $\mathrm{MH}$ professionals, and pharmacists in the treatment of chronic pain, the use of a wider range of professionals in the treatment of $\mathrm{MH}$ conditions, and the integration of $\mathrm{MH}$ professionals into traditional medical settings, such as primary care. This intentional move to a more well-integrated model of interprofessional care is apparent in many other health care systems throughout the United States. Within the VA, this shift may be most evident through the introduction of the Whole Health model of care. The Whole Health model of care uses an interprofessional team to assess and care for veterans, using a personalized health plan addressing medical and $\mathrm{MH}$ conditions as well as behavioral, social, or spiritual concerns. ${ }^{10}$ The Whole Health model of care provides veterans with access to a variety of health care services, including but not limited to MH services, spiritual interventions, exercise-based programs, yoga, meditation, and nutrition counseling.

The OAA and $\mathrm{AH}$ education division have focused expansion to meet the increased need for $\mathrm{MH}$ and rehabilitation providers, to enhance interprofessional education, and to emphasize postgradu- ate-degree clinical training. This focus reflects the trends seen in health care training broadly throughout the nation and the intentional pivot is a model of these trends and a model for how to intentionally address these trends. Specific to the VA, focused expansion plans have allowed OAA to address VA strategic initiatives such as pain management and caring for rural veterans.

\section{FUNDED TRAINING POSITIONS}

As a result of recent AH expansion efforts, there has been a 33\% increase in stipendfunded positions during the past 10 years, a rate that directly corresponds with the growth of AHPs in the VA. Recent AH expansion efforts can contribute to a particularly positive impact in highly rural and underserved areas where recruiting providers remains challenging.

The OAA launched the Mental Health Education Expansion (MHEE) initiative in 2012, which has now added 782 funded training slots across 10 health professions, 8 of which are psychology, pharmacy, chaplaincy, professional MH counseling, marriage and family therapy (MFT), social work (SW), occupational therapy (OT), and physician assistant (PA). Through the MHEE initiative, the VA has established funded internships for licensed professional mental health counselors and marriage and family therapists, as these professions are targeted for expanding the overall $\mathrm{MH}$ workforce in the VA. The OAA currently funds more than 50 total HPT positions for these 2 professions with an aim of increasing their recruitment to the VA MH workforce over the next decade. The MHEE is aligned with specified VA priorities to train a future VA workforce prepared for interprofessional collaboration and clinical care in an increasingly integrated and complex environment. This expansion effort also aligns with an increasing understanding of the importance of addressing the $\mathrm{MH}$ needs of our nation by ensuring there is an adequate supply of competent, well-trained clinicians entering the workforce.

The OAA has created and expanded residencies and fellowships in multiple rehabilitation professions, including chiropractic, physical therapy (PT), and OT. With the increased focus on the management of chronic 
pain in the nation combined with a specific emphasis on this clinical need in the VA, chiropractors have been deemed essential HCPs. In 2014, the VA established 5 chiropractic residency programs while partnering with the Council on Chiropractic Education to develop accreditation standards for residency training. OAA's efforts have yielded 5 accredited residency programs, the first in the United States. In 2020 , the VA doubled the number of available chiropractic residency programs, and future expansion is anticipated. Since 2010, PT residencies have expanded from 1 to 28 programs (42 funded positions) across 4 board certification specialties: cardiovascular-pulmonary, geriatric, neurologic, and orthopedic. Similarly, the VA was one of the first organizations to achieve accreditation for OT fellowships; there are currently 5 accredited OT fellowship programs across 3 areas of practice: assistive technology, $\mathrm{MH}$, and physical rehabilitation. The VA OT fellowship program focused on assistive technology is the only program in the United States at this time.

\section{Interprofessional Education}

As one of the primary focus areas for AH expansion, interprofessional education (IPE) has been recognized as increasingly important for the provision of health care and the development of HPT programs. IPE can develop professionals who appreciate the roles of diverse professions and can use teamwork to enhance clinical outcomes for patients. ${ }^{11}$ There also are a growing number of professional organizations supporting the Interprofessional Education Collaborative with many representing AHPs. ${ }^{12}$ Collaboration across HCPs is an important way of reducing health care costs by enhancing clinical outcomes, communication, and teamwork. ${ }^{13-16}$ The VA and the nation's health care system benefit from the by-products of interprofessional collaboration through investment in targeted training programs. In each phase of the $\mathrm{AH}$ expansion, special consideration was given to applicant programs offering unique and innovative clinical and educational experiences consistent with the promotion of interprofessional care. In doing so, increased numbers of AH HPTs have engaged in team-based clinical care.

\section{Pain Management Pharmacy}

The efforts of $\mathrm{AH}$ to align expansion with high-priority agency-wide efforts has resulted in the growth of pharmacy residency positions focused on pain management. Pharmacy postgraduate year (PGY) 2 residencies focusing on opioid reduction are an example of VA efforts to improve response to managing chronic pain and the long-term risks from opioid use during this national public health crisis. ${ }^{17}$ These residency programs focus on strategies to reduce the use of opioid medications in the clinical setting and teaching effective clinical interventions for reducing the rates of opioid addiction in veterans while still recognizing the need to identify and treat chronic pain. Before expansion efforts in 2018, there were 6 pharmacy residency programs focused on opioid use reduction in the VA, 8 pharmacy PGY2 residency positions were added in academic year 2019/2020, an additional 5 positions are being added in academic year 2021/2022 with the explicit goal of managing patients with high-risk chronic pain.

\section{Rural Health}

The lack of $\mathrm{MH}$ providers in rural areas has received much attention and is particularly important in the VA because veterans are more likely to live in less populated areas. ${ }^{18}$ The VA mandate to address this population was codified by the creation of the Office of Rural Health in 2006 via 38 USC $\S 7308 .{ }^{19}$ Creating health professions training programs in rural settings provides HPTs the opportunity to learn professional competencies and train with faculty knowledgeable about this population-all of which provide a comprehensive training experience and serve as a recruitment pathway to hire HPTs into staff positions at these sites. ${ }^{19}$

When MHEE was initiated, not all regions of the country had funded VA psychology training programs, and this geographic gap in psychology training was a contributing factor to recruitment difficulties for psychologists in rural areas. As a result, the request for proposal process in the OAA highlighted and incentivized rurality when considering funding for new training programs. The OAA defined rurality as the number of patients served by the proposed health care facility who lived in a rural or highly rural zip code according to VA Support Service Center 
Capital Assets data. ${ }^{20}$ As a result, VA psychology doctoral internships expanded to be available in all states, the District of Columbia, and Puerto Rico. $\mathrm{MH}$ training programs were started in the highly rural states of Montana and Wyoming. These expansion efforts promise to be an essential component to addressing the gaps in coverage in rural settings as noted in recent research. ${ }^{21}$

\section{Pregraduate to Postgraduate Programs}

The OAA AH education division supports a significant number of pregraduate-degree and postgraduate-degree training. Some professions, such as psychology, pharmacy, SW, PT, speech pathology, OT, and nutrition/dietetics receive funding at both levels of training. More recent, the OAA has started to move funding from pregraduate to postgraduate-degree positions, specifically within professions where pregraduate funding is uncommon for both federal and nonfederal training positions. The effort is designed to better align stipend-paid training programs with the VA Professional Qualification Standards and the final level of training required for employment in the VA. ${ }^{22}$ This means that HPTs receive stipend support during the highest level of their clinical training before degree conferral, eligibility for VA employment, or while participating in a postgraduate-degree residency or fellowship.

Additionally, this shift in focus and the resulting internal assessment of professions has allowed the OAA to fund more specialized training opportunities, which sometimes go beyond what is required by accrediting bodies or for recruitment into VA positions. For example, the OAA is supporting SW fellowship programs and PA residency positions to allow for greater specialization within these professions; the accrediting agencies for both professions have recently finalized their accreditation standards, and the OAA played a role in moving these standards forward.

While postgraduate residencies and fellowships are not required for all AH HPTs or for employment in the VA, there is a shift in some professions to encourage postgraduate training in advanced competencies in specialized areas. Participation in a residency or fellowship training program affords HPTs additional time and diverse clinical experiences to acquire clinical skills, all while under the supervision of a highly trained practitioner. This additional training also allows for a longitudinal assessment of the HPT to ensure an alignment of the HPTs' knowledge, abilities, and skills with the expectation should they pursue VA employment.

In academic year 2019/2020, the OAA $\mathrm{AH}$ education division in conjunction with the PA national program office transitioned the entirety of the PA pregraduate-degree student positions (415 funded positions) to residency positions, increasing residency positions from 19 to 32 funded positions. This shift in emphasis for funding did not negatively impact the total number of pregraduate PA students receiving training in the VA and has created a pipeline of residency graduates who are ready to enter VA staff positions. To date, the VA has 14 PA residency programs across 3 specialties: emergency medicine (EM), MH, and primary care/geriatrics. Of these tracks, the VA offers $5 \mathrm{EM}$ and $4 \mathrm{MH}$ residencies that position graduates to be eligible for specialty certification. The National Commission on Certification of Physician Assistants established Certificates of Added Qualifications (CAQ) to recognize and document specialty knowledge, skills, and experience. The VA MH residency programs have been established to align with the CAQ expectations, and residents immediately qualify to take the CAQ examination after the completion of training.

Currently, the same process to move pregraduate to postgraduate funding is being implemented for PT and OT. Within the PT profession, there is increased momentum toward residency and fellowship training programs to respond to the changing complexity of the health care system and reduce the need of complex care to be provided by non-VA providers in the community. ${ }^{23}$ Both PT and OT have entered the initial phases of transitioning to residency or fellowship-funded positions. The OAA is partnering with these professions to move positions to postgraduate degree within the next 3 years with a commensurate increase in funding. The initial data indicate that $80 \%$ of graduated VA PT residents are board-certification eligible, and $89 \%$ of those who are eligible passed the 
examination on their first attempt.

Since 2013, the VA psychology training also has realized a growth in postgraduate-degree residencies. Psychology residency positions have increased $99 \%$ to 453 funded positions. This growth represents increased specialization in neuropsychology, geropsychology, rehabilitation psychology, and health psychology. Additionally, postgraduate residencies meet most jurisdictional requirements for postdoctoral supervised experience and better prepare HPTs to enter specialty staff positions that are necessary to care for aging veterans.

Additional professions are being targeted for postgraduate-degree training programs, including dietetics and speech pathology, to align with upcoming changes in the qualification standards for employment. While the process to transition positions to postgraduate-degree training programs can take 3 to 5 years, the outcomes are expected to result in better prepared HPTs who can fill staff vacancies in the VA.

\section{CONCLUSIONS}

Through its funding and oversight of numerous professions, the OAA is uniquely situated to adapt its portfolio to meet the needs of the VA and the nation. Over the past 10 years, the OAA has expanded its total number of HPT positions to enhance interprofessional care, respond to the VA's strategic initiatives, address the care needs of rural veterans, and shift positions to postgraduate training programs. The OAA's investment in high-quality training programs builds a strong health care workforce ready to meet the needs of an increasingly complex and integrated health care environment.

The OAA anticipates future expansion, especially related to promoting rural training opportunities and shifting to postgraduate training programs as a means of promoting advanced health care and health system competencies while continuing to align with workforce projections. Furthermore, while there are data on the percentage of VA staff who participated in OAA training program through the VA All Employee Survey (AES), the range for $\mathrm{AH}$ professions is wide. For example, about $37 \%$ of rehabilitative staff reported participating in an OAA training program, and $72 \%$ of VA psychologists reported having an OAA training experience.
To maximize the hiring of HPTs, OAA will continue its partnership with WMC to enact programs aimed at streamlining the hiring process so that veterans have access to HCPs who are specifically trained to work with them.

\section{Author disclosures}

The authors report no actual or potential conflicts of interest with regard to this article.

\section{Disclaimer}

The opinions expressed herein are those of the authors and do not necessarily reflect those of Federal Practitioner, Frontline Medical Communications Inc., the US Government, or any of its agencies.

\section{Author affiliations}

Erin Patel is an Acting Chief, Health Professions Education; Jeffrey Bates is an Acting Director, Associated Health; Jocelyn Holguin and Stacy Pommer are National Affiliations Officers, Associated Health; Samuel King is a Statistician, Associated Health; Paul Greenberg is an Acting Chief Academic Affiliations Officer; Karen Sanders is a Senior Advisor; all in Office of Academic Affiliations, Veterans Health Administration, US Department of Veterans Affairs (VA). Anthony Albanese is Chief of Medicine, VA Northern California Health Care System. Marjorie Bowman is an Acting Assistant Under Secretary for Health, Discovery, Education and Affiliate Networks, Veterans Health Administration, US Department of Veterans Affairs. Paul Greenberg is a Professor of Surgery (Ophthalmology), Alpert Medical School, Brown University in Providence, Rhode Island. Anthony Albanese is a Clinical Professor of Medicine (Gastroenterology, Hepatology, Addiction Medicine) at UC Davis School of Medicine in Sacramento, California. Karen Sanders is a Professor, Internal Medicine, Division of Rheumatology, Allergy and Immunology at Virginia Commonwealth University School of Medicine in Richmond, Virginia. Marjorie Bowman is an Emeritus Professor at University of Pennsylvania in Philadelphia.

\section{References}

1. US Department of Veterans Affairs. Providing health care for veterans. Updated April 23, 2021. Accessed July 15, 2021. https://www.va.gov/health

2. Veterans' Benefits. 38 USC $\S 7301$ and $\S 7302$ (1991). Accessed May 18, 2020. https://www.govinfo.gov/content /pkg/USCODE-2018-title38/pdf/USCODE-2018-title38 -partV-chap73-subchapl-sec7302.pdf

3. US Department of Veterans Affairs, Veterans Health Administration, Office of Academic Affiliations. Health professions education: academic year 2019-2020. Published 2021. Accessed July 15, 2021. https://www.va.gov/OAA/docs/OAA Statistics_2020.pdf

4. US Department of Veterans Affairs, VHA Office of Academic Affiliations. VA Policy Memorandum \# 2. Policy in association of veterans' hospitals with medical schools. Published January 30, 1946. Accessed October 13, 2020. https:// www.va.gov/oaa/Archive/PolicyMemo2.pdf

5. US Department of Veterans Affairs, Veterans Health Administration, Office of Academic Affiliations. Mission of the office of academic affiliations. Updated September 24, 2019. Accessed July 15, 2021. https://www.va.gov loaa/oaa_mission.asp

6. US Bureau of Labor Statistics, Office of Occupational Statistics and Employment Projections Occupational Outlook Handbook. Healthcare occupations. Updated May 14, 2021. Accessed July 15, 2021. https://www.bls.gov/ooh /healthcare/home.htm

7. Windmill IM, Freeman BA. Demand for audiology services: 30-yr projections and impact on academic programs. J Am Acad Audiol. 2013;24(5):407-416. doi:10.3766/jaaa.24.5.7 
8. US Department of Health and Human Services, Health Resources and Services Administration, Bureau of Health Workforce. HRSA health workforce: behavioral health workforce projections, 2017-2030. Accessed July 15, 2021. https://bhw.hrsa.gov/sites/default/files/bureau-health-work force/data-research/bh-workforce-projections-fact-sheet.pdf

9. Centers for Disease Control and Prevention, National Center for Health Statistics. NCHS data brief, No. 325. Use of yoga, meditation, and chiropractors among US adults aged 18 and over. Published November 2018. Accessed September 24, 2020. https://www.cdc.gov/nchs/data /databriefs/db325-h.pdf

10. US Department of Veterans Affairs, Veterans Health Administration Whole Health. Updated July 6, 2021. Accessed July 15, 2021. https://www.va.gov/wholehealth

11. Clark KM. Interprofessional education: making our way out of the silos. Respir Care. 2018;63(5): 637-639. doi:10.4187/respcare.06234

12. Interprofessional Education Collaborative. What is interprofessional education (IPE)? Accessed July 15, 2021. https:// www.ipecollaborative.org/about-us

13. Nester J. The importance of interprofessional practice and education in the era of accountable care. N C Med J. 2016;77(2):128-132. doi.10.18043/ncm.77.2.128

14.. Hardin L, Kilian A, Murphy E. Bundled payments for care improvement: preparing for the medical diagnosis-related groups. J Nurs Adm. 2017;47(6): 313-319. doi:10.1097/NNA.0000000000000492

15. Guraya SY, Barr $\mathrm{H}$. The effectiveness of interprofessional education in healthcare: a systematic review and metaanalysis. Kaohsiung J Med Sci. 2018;34(2):125-184 doi:10.1016/j.kjms.2017.12.009

16. Ateah CA, Snow W, Wenter $P$, et al. Stereotyping as a barrier to collaboration: does interprofessional education make a difference? Nurse Educ Today. 2011;31(2):208-213. doi:10.1016/j.nedt.2010.06.004

17. US Department of Veterans Affairs, US Department of Defense. VA/DoD Clinical Practice Guideline for Managing Opioid Therapy for Chronic Pain. Published May 7 , 1991. Updated February 2017. Accessed July 15, 2021. https://www.va.gov/HOMELESS/nchav/resources/docs /mental-health/substance-abuse/VA DoD-CLINICAL -PRACTICE-GUIDELINE-FOR-OPIOID-THERAPY-FOR -CHRONIC-PAIN-508.pdf

18. US Department of Veterans Affairs, Office of Rural Health VHA office of rural health. Updated March 17, 2021. Accessed July 15, 2021. https://www.ruralhealth.va.gov

19. Curran V, Rourke J. The role of medical education in the recruitment and retention of rural physicians. Med Teach. 2004;26(3):265-272. doi:10.1080/0142159042000192055

20. US Department of Veterans Affairs. VHA Support Service Center Capital Assets. Updated December 1, 2020. Accessed July 15, 2021. https://www.data.va.gov/dataset NHA-Support-Service-Center-Capital-Assets-VSSC -/2fr5-sktm

21. Domino ME, Lin CC, Morrisey JP, et al. Training psychologists for rural practice: exploring opportunities and constraints. J Rural Health. 2019;35(1):35-41. doi:10.1111/jrh.12299

22. US Department of Veterans Affairs. VA Directive 5005: Staffing. Published March 4, 2020. Accessed July 15, 2021. https://www.va.gov/vapubs/viewPublication.asp?Pub ID=1140\&FType=2

23. Furze JA, Freeman BA. Physical therapy and fellowship education: reflections on the past, present, and future. Phys Ther. 2016;96(7):949-960. doi:10.2522/ptj.20150473 